\title{
Silver Nanoparticles Formation by Nanosecond Pulsed Laser Irradiation in an Aqueous Solution of Silver Nitrate; Effect of Sodium bis (2-ethyl hexyl) Sulfosuccinate
}

\author{
Umair Yaqub Qazi*
}

Department of Chemistry, College of Science, University of Hafr Al Batin. P.O Box 1803 Hafr Al Batin 39524, Kingdom of Saudi Arabia

Corresponding Author Email: umairqazi@uhb.edu.sa; umair_qazi@yahoo.com

\begin{abstract}
A photochemical reduction of a silver salt precursor using near-ultra-violet (UV) pulsed laser (355 nm) irradiation into aqueous surfactant sodium-bis (2-ethylhexyl) sulfosuccinate (AOT) solution has succeeded in synthesizing homogenous speculative silver nanoparticles (Ag NPs). Without using any additive, the irradiation from ns laser pulses to aqueous silver nitrate solution was observed to create nanocubes (NCs). The photoproduct was transformed into a nanosphere when irradiated with a particular AOT concentration. The photoproduct concentration of NCs to NSs was approximately ten times lower than the critical concentration of micellar (CMC) in AOT, which means that the growth of NSs was aided in a single layer of AOT adsorbed on silver surfaces. A UV/Visible Spectrophotometer and Transmission/Scanning electron microscopy (TEM/SEM) were used to characterize the photochemically synthesized sample thoroughly. The mean size of AgNSs, analyzed by TEM, was $8 \mathrm{~nm}$. These parameters have shown the growth of AgNSs and discussed in the paper. These nanoparticles are potential candidates for catalyst, semiconductor, photovoltaic equipment, medical diagnostics applications than bulk materials.
\end{abstract}

Keywords: Critical micelles concentration (CMC), Silver nanospheres (AgNSs), Laser irradiation, Nanotechnology, sodium-bis (2ethylhexyl) sulfosuccinate (AOT)

Received: November-18-2020, Accepted: January-28-2021, https://doi.org/10.14447/jnmes.v24i1.a07

\section{INTRODUCTION}

The fastest-growing field of development in the world is nanotechnology, and researchers are involved in developing new nanomaterials through new and straightforward processes[1-7]. In the past few decades, the field of nanotechnology has shown remarkable successes, with various methodologies devised for the synthesis of nanoparticles of unique shapes and dimensions in compliance with specific requirements[8-15]. Clean synthesis approaches to prevent the use of harmful chemicals are being established with considerable interest, and synthesized products are utilized for medicinal and pharmaceutical uses[16-21]. The optical, electric, magnetic, and pharmaceutical characteristics of these nanostructures have improved favorably and make them potential candidates for catalyst, semiconductor, photovoltaic equipment, medical diagnostics, and treatment applications compared with bulk materials[22-27]. Most of the strategies suggested are based on chemical products such as reduction of metal ion converters, capping agents for the production of traditional types, and suspension maintenance stabilizers. Since these chemicals should be extracted subsequently, according to NPs usage, manufacturing processes with fewer chemicals are preferred from the application perspective. For this purpose, photoreduction has been suggested rather than reducing agents. In the NP formation process, the position of chemical additives remained unclear[28-33]. Reducing agents can act as capping agents that control the final form of the NPs, or capping agents and stabilizers could be chemical or photochemically oxidized by catalytic NPs, resulting in the growth of NPs by metal ion adsorption. It seems complicated to explain the individual functions of the added chemicals as long as we rely on such additives [34-38].

In this article, we suggest the use of UV radiation in an aqueous solution to reduce silver nitrate. This research has provided us with a new technique for generating uniform NPs with fewer additives. Moreover, we have been able to explore the NP formation process. We have reported this significant study in our previous research work with Sodium Dodecyl Sulphate (SDS) as an additive[39-41]. Herein, we have investigated how Sodium bis (2-ethyl hexyl) sulfosuccinate (AOT) influences the formation of silver $n p$ by changing a standard AOT concentration and observed the formation of nanocubes (NCs) without the presence of any additives; however, Stable, unified Nanospheres (NSs) were produced with a critical micellar concentration (CMC) of AOT even ten times lower. The effect of the low concentration of AOT can be explained with the maximum one-layer coverage of AOT anions' silver NS surfaces above its critical hemi-micellular concentration (HMC).

\section{EXPERIMENTAL}

\section{Materials}

Silver nitrate of $99.9 \%$ purity was received from SigmaAldrich. Sodium bis (2-ethyl hexyl) sulfosuccinate (AOT) were purchased from Wako Pure Chemicals, Co. Japan. Ultrapure water was used for the preparation of sample solutions (Millipore, $18 \mathrm{M} \Omega . \mathrm{cm}$ ).

In a typical quartz cell $\left(10 \times 10 \times 45 \mathrm{~mm}^{3}\right)$ with a magnetic stirrer, silver nitrate dissolves in ultra-pure water. It is 
irradiated with UV-laser pulses (Quantel Brilliant, $355 \mathrm{~nm}$ wavelength, $6 \mathrm{~ns}$ pulse width, $10 \mathrm{~Hz}$ repetition). The quartz cell was positioned on a magnet plate. The solution was mixed to radiate the solution evenly by the placement of a magnetic bar and moving it to a rate of $110 \mathrm{rpm}$ inside the cuvette. The cumulative volume of solution with or without a certain quantity of AOT was set to $3 \mathrm{~mL}$. The laser beam $(4.6 \mathrm{~mm}$ diameter) has been illuminated without a focus lens employing on a solution. A small portion of the solution was taken for the sample preparation after a particular time $(30 \mathrm{~min})$ of laser irradiation and then observed in a TEM. Figure 1 displays the schematic representation of the experimental set-up.

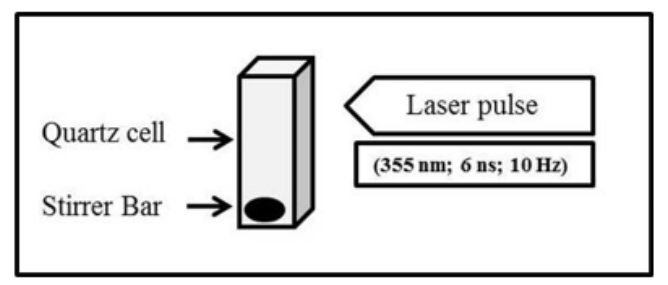

Figure 1. Experimental setup for AgNPs using ns pulsed laser irradiation in an aqueous solution $\mathrm{AgNO}_{3}$

\section{Characterization techniques}

Naked eyes watch the visual monitoring of the photochemical reduction from silver salt precursor to silver metal. It has been reported the UV-spectrum of preparations, which were one of the most common techniques used to characterize metallic nanomaterials. The colorless precursor solution converted to light yellow or dark yellow is the hallmark of Ag NP formation with Ag precursor Salt solution subjected to the pulsed laser. The existence of the mono scattered Ag NPs has been confirmed at $400 \mathrm{~nm}$ by the sharp resonance band. For spectral recoding, UV-visible spectrophotometer Shimadzu UV-1600 was used. The morphology and microstructure of the samples were investigated with an acceleration voltage of $200 \mathrm{kV}$ by transmission electron microscopy (TEM) and HRTEM by a JEM 2010 transmission electron microscope. Drop casting a small part of photo reduced stock on ITO substrates and drying in a desiccator is used to prepare SEM sample. In order to determine the structure and size of Ag NP, SEM images were recorded on Hitachi's FE-SEM-S4300 devices with 20.0 KV. Dynamic laser light scattering (DLS) equipment was used to determine the size distribution of the particles. A highperformance digital light scattering (DLS) particle size analyzer Malvern Instrument Co., MAL501088, was used to determine the size of the synthesized Ag NPs. A highperformance digital light scattering (DLS) particle size analyzer Malvern Instrument Co., MAL501088, was used to determine the size of the synthesized Ag NPs. DLS is known to quantify the size of the particles, including stabilizing agent size and the real metallic core size of the materials.

\section{RESULT AND DISCUSSION}

Silver nitrate as a silver salt precursor was dissolved into ultrapure water $\left(2 \times 10^{-4} \mathrm{M}\right)$. AOT was introduced in this experiment in place of SDS as discussed in the previous research findings of our research group. AOT has CMC at $1.4 \times 10^{-3} \mathrm{M}$ [42]. Silver salt concentration was kept constant in all experiments; however, AOT concentration varies from $3.5 \times 10^{-5}-7 \times 10^{-4} \mathrm{M}$. AOT's molecular structure comprises 20 carbon atoms that form centrally connected long-chain hydrocarbons and sulfate groups. Various molecular configurations can have various impacts on synthesized product growth, size, and shape. Detailed studies have been undertaken to maintain these points.

\subsection{Optical properties [Aerosol OT (AOT)]}

Prior to Laser Irradiation, the sample solution was clear but turned pale yellow, suggesting the formation of AgNPs. Photographs of samples taken before and after laser irradiation are shown in Figure 2. Following different irradiation time, Figure 3 displays absorption spectra. The presence of spherical AgNPs is shown by a surface plasmon absorption band with a maximum height of $396 \mathrm{~nm}$. Previous researchers reported that the $395 \mathrm{~nm}$ absorption peak coincides with small spherical nanoparticles with a particle size of 1-10 $\mathrm{nm}$ [43-45].

The absorption spectrum was observed that did not increase without AOT concentration; however, the absorption peak at $396 \mathrm{~nm}$ increased when the AOT was increased.

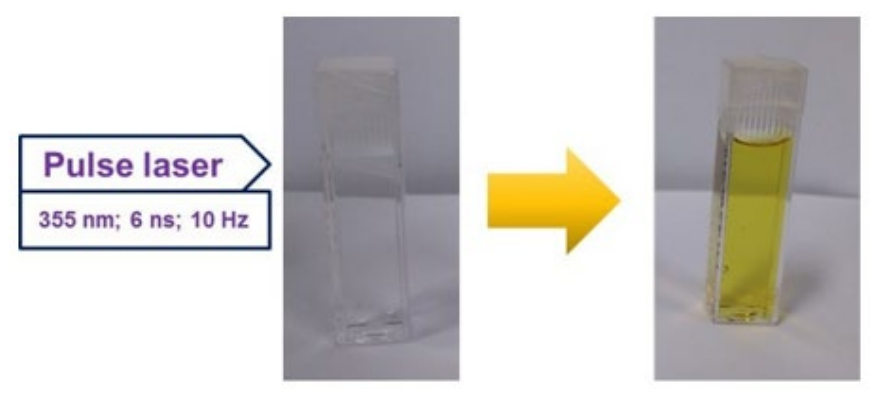

Figure 2. Photographs taken before and after ns laser irradiation (0.2 mM AgNO3; $0.7 \mathrm{mM} \mathrm{AOT).} \mathrm{Transparent} \mathrm{sample} \mathrm{solution}$ turned light yellow
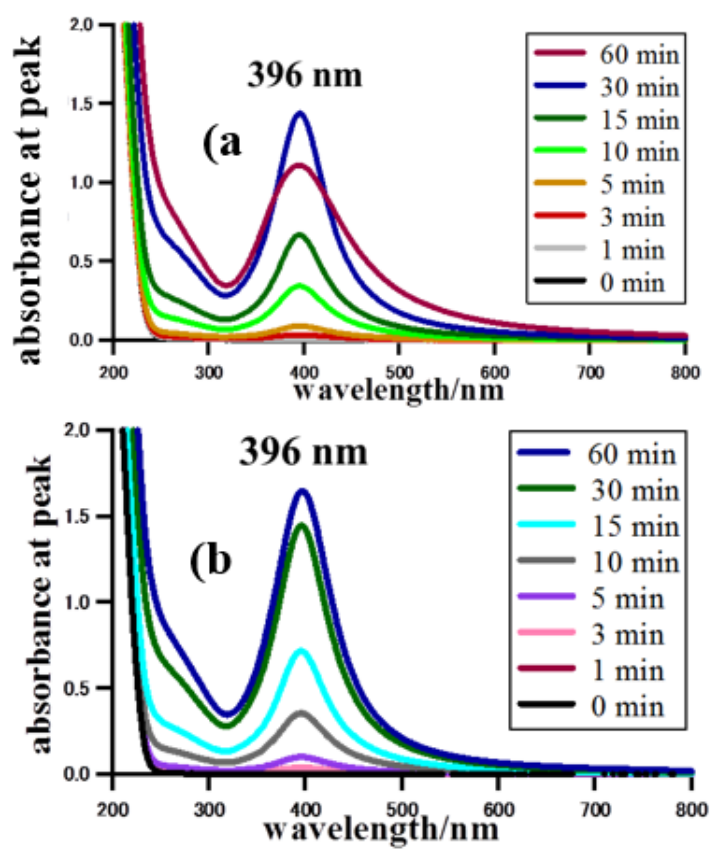

Figure 3. Absorbance spectra showing nanoparticle growth: (a) $[\mathrm{AOT}]=2 \times 10-4 \mathrm{M}$; (b) $[\mathrm{AOT}]=7 \times 10-4 \mathrm{M}$. Laser intensity was $300 \mathrm{~mJ} / \mathrm{cm} 2$ and the silver nitrate concentration was $2 \times 10-4 \mathrm{M}$ 
The absorption spectrum showed no change, which means that synthesized products did not increase or alter in size during the laser irradiation of a certain time. After the longterm irradiation based on AOT, the absorption peak stopped increasing. Afterward, further irradiation only transferred the spectral type to longer wavelengths that suggest a redshift after 60 min irradiation seen in Figure 3(a). It is suggested that after a long time of laser irradiation, NSs will start to add, expand in size, or change shapes on the AOT concentration $\left(<7 \times 10^{-4}\right.$ $M)$. Figures 3(b) did not even alter the absorption spectrum of nanoparticles over 60 minutes, which means that nanoparticles were saturated at this absorption value. Furthermore, the silver ions present in the solution were fully consumed.

\subsection{Morphology and size distribution}

Measurements for the size and polydispersity of AgNPs have been carried out by TEM and DLS. Samples were prepared by irradiating a silver salt solution and AOT for 30 minutes. Typical TEM images from silver nitrate solution with AOT are shown in Figure 4. Particles with an average particle size of $8 \mathrm{~nm}$ are of a spherical and monodispersed form. Histogram bars of particles' size measured by DLS are also shown in Figure 4.

Without AOT several various photo products and aggregates were developed [46]. NCs of similar sizes have been discovered among images, and their sizes have evolved through repeated irradiation from a few nm to sub-micron (supporting information; S1, S2). The inclusion of AOT greatly altered the photoproducts of uniform NSs with an average diameter of $8 \mathrm{~nm}$. The results show that a variety of NPs can be created, along with NCs, if a photoreduction of silver ions coagulates the silver atom produced in the water and the NS is created mainly by AOT. Reports have shown that no additives but chemical reducers, such as glucose, can be allowed to treat with NSs $[47,48]$. In some instances, we believe that these reduction agents can also be used as capping agents to form unique NP.

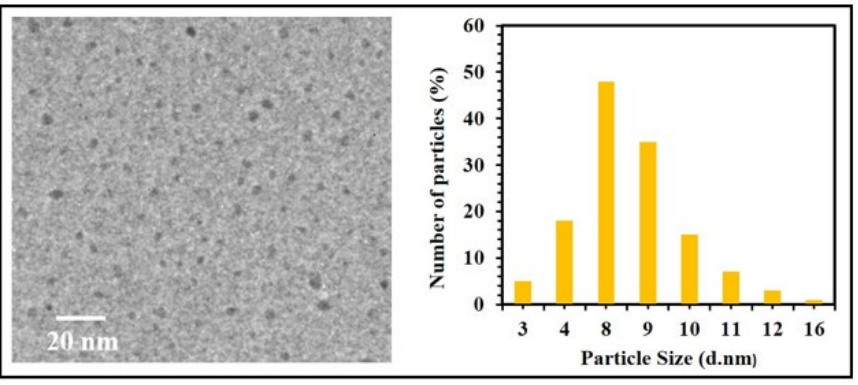

Figure 4. TEM images of nanoparticles formed by laser irradiation $\left(355 \mathrm{~nm}, 290 \mathrm{~mJ} / \mathrm{cm}^{2}, 10 \mathrm{~Hz}, 30 \mathrm{~min}\right)$ to silver nitrate aqueous solution with AOT and Particle size distributions by DLS

\subsection{Time profile of AOT with various concentrations}

Figure 5 displays the growth time profile of AgNPs aided by different AOT concentrations, where the growth phase can be seen at a short and a long time window. The absorption spectra findings explicitly show that the NPs in the solution improved, but a certain value does not help the growth process. The absorption grew drastically over this specific concentration, which correlates to our previous results of the SDS findings [39]. It ensures that AOT molecules on the surface of NPs help the growth process. The AOT value below
10 times lower than the CMC was also noted as incapable of helping the growth process which is almost the same as for SDS and addressed in depth. The mechanism of development must be addressed in the same way as SDS, which was discussed by Umair et al. [39].

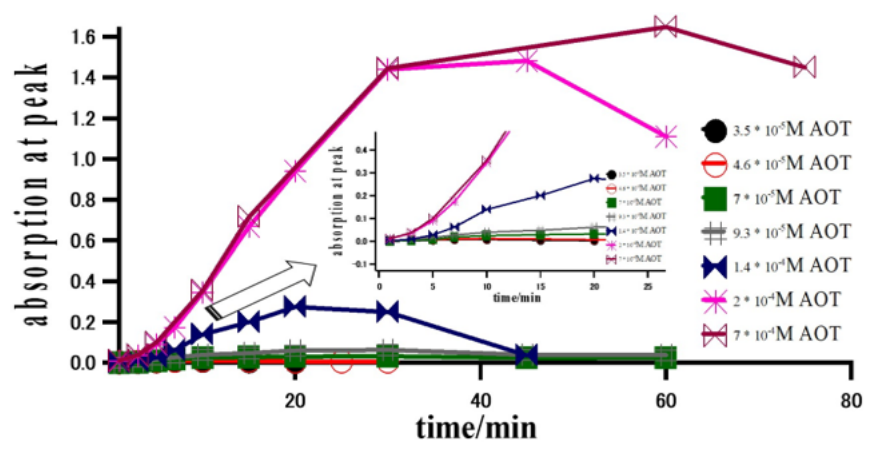

Figure 5. Growth of the peak absorbance with UV laser irradiation $(300 \mathrm{~mJ} / \mathrm{cm} 2)$. AOT concentration varies from $3.5 \times 10-5-7 \times 10-4$ $\mathrm{M}$ while silver nitrate concentration is $2 \times 10-4 \mathrm{M}$. Arrow indicates the enlarged image at short time scale

\subsection{Effect of AOT concentration on NPs formation process}

The maximal absorption image as a function of different AOT concentrations is seen in Figure 6. The arrow displays the lowest AOT limit at which NP development grew. This value is ten times less than the CMC value $\left(1.4\right.$ to $\left.10^{-3} \mathrm{M}\right)$ of AOT. The lowest concentration at which the growth phase will continue to expand falls between the range $9.3 \times 10^{-5}$ and $1.4 \times 10^{-4} \mathrm{M}$. It is commonly recognized that below $\mathrm{CMC}$, mainly surfactant molecules will form dimers and free monomers in aqueous solutions[49,50]. At CMC, the development of soft templates in the solution occurs, whereas surfactants with a concentration lower than CMC do not act as soft templates. These results support the concept of hemimicellar formation into the solution as discussed by Umair et al[39].

\subsection{Role of AOT on the growth process}

The role of AOT in promoting the growth of NSs with such low concentrations can be clarified by the interaction between silver NS surfaces and AOT molecules, as has already been pointed out. AOT molecules like SDS have been documented to form two-dimensional aggregates (hemi-micelles) at the water and a charged aluminum interface, also at a low SDS concentration [51, 52]. Different experimental methods have shown that AOT adsorption density on a positively charged surface increases significantly with an AOT balance concentration approximately 10 times smaller than its CMC. Two distinct regions are depending on the concentration of AOT to form hemi-micelles at the interface.: 1) the area with a sharp increase in the AOT adsorption density due to electrostatic attraction and additional lateral interactions among hydrocarbon chains; 2) an area where the adsorption by AOT neutralizes positive charged surfaces, and there is more progressive adsorption with a hydrophobic interaction creating partly dual interface layers. The transformation between both regions occurs around one order less than $\mathrm{CMC}$ at an AOT equilibrium concentration, that coincides in this experiment exactly with the increasing critical concentration of NS. This structure of hemi-micellar AOT is also confirmed by ellipsometry on a positive electrode [52]. We assume that NS's 
development can be accelerated by completely covering and neutralizing the adsorption of the AOT monolayer with positive silver-coated surfaces.

\section{CONCLUSION}

Initially, we demonstrated the synthesis with $355 \mathrm{~nm}$ pulsed laser irradiation for stable Ag NPs of an average size of $8 \mathrm{~nm}$ from their salt. Herein, we analyzed the influence of the AOT additive on the mechanism of AgNPs development. These findings open the way for an interpretation of the form to regulates the reaction and suggest AOT plays a significant role in regulating both the shapes and size of NPs. The hydrocarbon chain also impacts the NPs fabrication process. We observed that the hydrocarbon chain $>10$ carbon atoms (AOT) showed the CGC. This was the lowest level to start growing the NPs.and bigger molecules control the morphology of AgNPs. As far as we know, the AOT additive's possible impact is being explicitly addressed with the light as the reducing agent for the first time. For stabilized Ag NPs it is a strong hemi-micellar or pre-micellular concentration of AOT.

\section{ACKNOWLEDGMENT}

Dr. Umair Yaqub Qazi extend his appreciation to the Deanship of Scientific Research, University of Hafr Al Batin for funding this work through the research group project No. G-122-2020. Dr. Umair Yaqub Qazi is also thankful for the usage of laboratory instruments and technical assistance at Tohoku University.

\section{REFERENCES}

[1] Qazi UY, Shervani Z, Javaid R., Front Nanosci Nanotechnol, 4, 61 (2018). https://doi.org/10.4236/anp.2015.43008.

[2] Javaid R, Qazi UY, Kawasaki SI., J Environ Manage, 180, 551(2016). https://doi.org/10.1016/j.jenvman.2016.05.075.

[3] Javaid R, Nanba T., Int J Hydrogen Energy, https://doi.org/10.1016/j.ijhydene.2020.07.222.

[4] Javaid R, Matsumoto H, Nanba T., ChemistrySelect, 4, 2218 (2019). https://doi.org/10.1002/slct.201803813.

[5] Javaid R, Aoki Y, Nanba T., ChemistrySelect, 5, 4312 (2020). https://doi.org/10.1002/slct.202000883.

[6] Nanba T, Javaid R, Matsumoto H., Catalysts and Catalysis, 16, 66 (2019).

[7] Anba TN, Agata YN, Obayashi KK, Avaid RJ, Tsumi RA., Journal of the Japan Petroleum Institute, 64, 1 (2021). https://doi.org/10.1627/jpi.64.1

[8] Tabasum A, Alghuthaymi M, Qazi UY, Shahid I, Abbas Q, Javaid R, et al., Plants, 10, 1 (2021). https://doi.org/10.3390/plants10010006.

[9] Afzal A, Mujahid A, Iqbal N, Javaid R, Qazi UY., Nanomaterials (Basel), 10(11), 2133 (2020). https://doi.org/10.3390/nano10112133.

[10] Afzal A, Abuilaiwi FA, Javaid R, Ali F, Habib A., J Mater Sci Mater Electron, 31, 14261 (2020). https://doi.org/10.1007/s10854-020-03982-8.

[11] Qazi UY, Javaid R, Talib N, Jamil A, Adeel A., Int J Hydrogen Energy, 45, 3396 (2020).

https://doi.org/10.1016/j.ijhydene.2020.09.026.
[12] Javaid R, Aoki Y, Nanba T., J Phys Chem Solids, 146, 109570 (2020). https://doi.org/10.1016/j.jpcs.2020.109570.

[13] Dimitriou P, Javaid R., Int J Hydrogen Energy, 45, 7098 (2020). https://doi.org/10.1016/j.ijhydene.2019.12.209.

[14] Javaid R, Urata K, Furukawa S, Komatsu T., Appl Catal A Gen, 491, 100 (2015). https://doi.org/10.1016/j.apcata.2014.12.002.

[15] Javaid R, Qazi UY, Kawasaki SI., Bull Chem Soc Jpn, 88, 976 (2015). https://doi.org/10.1246/bcsj.20150052.

[16] Shervani Z, Khan I, Khan T, Qazi UY., Adv Infect Dis, 10, 195 (2020). https://doi.org/10.4236/aid.2020.103020.

[17] Rahman A, Zulfiqar S, Haq AU, Alsafari IA, Qazi UY, Warsi MF, et al., Ceram Int, 47, 9513 (2020). https://doi.org/10.1016/j.ceramint.2020.12.085.

[18] Shervani Z, Khan I, Qazi UY., Adv Infect Dis, 10, 56 (2020). https://doi.org/10.4236/aid.2020.103007.

[19] Ullah N, Imran M, Liang K, Yuan CZ, Zeb A, Jiang N, et al., Nanoscale, 9, 13800 (2017). https://doi.org/10.1039/c7nr05096h.

[20] Zou HH, Yuan CZ, Zou HY, Cheang TY, Zhao SJ, Qazi UY, et al., Catal Sci Technol, 7, 1549 (2017). https://doi.org/10.1039/c7cy00035a.

[21] Hu L, Hao GX, Luo HD, Ke CX, Shi G, Lin J, et al., Cryst Growth Des, 18, 2883 (2018). https://doi.org/10.1021/acs.cgd.7b01728.

[22] Rycenga M, Cobley CM, Zeng J, Li W, Moran CH, Zhang Q, et al., Chem Rev, 111, 3669 (2011). https://doi.org/10.1021/cr100275d.

[23] El-Sayed MA., Acc Chem Res, 34, 257 (2001). https://doi.org/10.1021/ar960016n.

[24] Yuan CZ, Sun ZT, Jiang YF, Yang ZK, Jiang N, Zhao ZW, et al., Small, 13, 1604161 (2017). https://doi.org/10.1002/smll.201604161.

[25] Qazi UY, Javaid R., Adv Nanoparticles, 5, 27 (2016). https://doi.org/10.4236/anp.2016.51004.

[26] Qazi UY, Yuan CZ, Ullah N, Jiang YF, Imran M, Zeb A, et al., ACS Appl Mater Interfaces, 9, 28627 (2017). https://doi.org/10.1021/acsami.7b08922.

[27] Javaid R, Kawanami H, Chatterjee M, Ishizaka T, Suzuki A, Suzuki TM. Sonogashira, Chem Eng J, 167, 431 (2011). https://doi.org/10.1016/j.cej.2010.08.080.

[28] Javaid R, Kawanami H, Chatterjee M, Ishizaka T, Suzuki A, Suzuki TM., Catal Commun, 11, 1160 (2010). https://doi.org/10.1016/j.catcom.2010.05.018.

[29] Javaid R, Tanaka DAP, Kawanami H, Suzuki TM., Chem Lett, 38, 146 (2009). https://doi.org/10.1246/cl.2009.146.

[30] Javaid R, Kawasaki S-I, Suzuki A, Suzuki TM., J Org Chem, 9, 1156 (2013). https://doi.org/10.3762/bjoc.9.129.

[31] Javaid R, Kawasaki S-I, Ookawara R, Sato K, Nishioka M, Suzuki A, et al., J Chem Eng Japan, 46, 751 (2013). https://doi.org/10.1252/jcej.13we184.

[32] Javaid R, Qazi UY., Int J Environ Res Public Health, 16, 2066 (2019). https://doi.org/10.3390/ijerph16112066.

[33] Nanba, Tetsuya; Javaid, Rahat; Matsumoto H., Fine Chem, 48, 6 (2019).

[34] López-Miranda A, López-Valdivieso A, ViramontesGamboa G., J Nanoparticle Res, 14, 1 (2012). https://doi.org/10.1007/s11051-012-1101-4.

[35] Nakamura T, Magara H, Herbani Y, Sato S., Appl Phys A Mater Sci Process, 104, 1021 (2011). https://doi.org/10.1007/s00339-011-6499-5.

[36] Wiley B, Sun Y, Xia Y., Acc Chem Res, 40, 1067 (2007). https://doi.org/10.1021/ar7000974.

[37] Pileni MP., Nat Mater, 2, 145 (2003). 
https://doi.org/10.1038/nmat817.

[38] Javaid R, Nanba T., Optimization of reaction conditions for ammonia synthesis using $\mathrm{Ru} / \mathrm{Cs} / \mathrm{MgO}$ catalyst. WHEC 2016 - 21st World Hydrog. Energy Conf. 2016, Proc., 2016.

[39] Qazi UY, Kajimoto S, Fukumura H., Chem Lett, 43, 1693 (2014). https://doi.org/10.1246/cl.140617.

[40] Zeb A, Sahar S, Qazi UY, Odda AH, Ullah N, Liu YN, et al., Dalt Trans, 47, 7344 (2018). https://doi.org/10.1039/c8dt01146j.

[41] Imran M, Zhou X, Ullah N, Liu YN, Zeb A, Jiang N, et al., ChemistrySelect, 2, 8625 (2017). https://doi.org/10.1002/slct.201702088.

[42] Aniansson EAG, Wall SN, Almgren M, Hoffmann H, Kielmann I, Ulbricht W, et al., J Phys Chem, 80, 905 (1976). https://doi.org/10.1021/j100550a001.

[43] Langille MR, Personick ML, Mirkin CA., Angew Chemie Int Ed, 52, 13910 (2013).

https://doi.org/10.1002/anie.201301875.

[44] Stamplecoskie KG, Scaiano JC., Photochem Photobiol, 88, 762 (2012).

https://doi.org/10.1111/j.1751-1097.2012.01103.x.
[45] González AL, Noguez C, Beránek J, Barnard AS., J Phys Chem C, 118, 9128 (2014). https://doi.org/10.1021/jp5018168.

[46] Qazi UY, Shervani Z, Javaid R, Kajimoto S, Fukumura H., Adv Nanoparticles, 6, 148 (2017). https://doi.org/10.4236/anp.2017.64013.

[47] Kvitek L, Vanickova M, Panacek A, Soukupov J, Dittrich M, Valentova E, et al., J Phys Chem C, 113, 4296 (2009). https://doi.org/10.1021/jp808645e.

[48] Swensson B, Ek M, Gray DG., ACS Omega, 3, 9449 (2018). https://doi.org/10.1021/acsomega.8b01199.

[49] Szutkowski K, Kołodziejska Z, Pietralik Z, Zhukov I, Skrzypczak A, Materna K, et al., RSC Adv. 8, 38470 (2018). https://doi.org/10.1039/c8ra07081d.

[50] Azum N, Kumar D., Sci Rep, 10, 1 (2020). https://doi.org/10.1038/s41598-020-61001-6.

[51] Somasundaran P, Healy TW, Fuerstenau DW., J Phys Chem, 68, 3542 (1964). https://doi.org/10.1021/j100794a021.

[52] Somasundaran P, Fuerstenau DW., J Phys Chem, 70, 90 (1966). https://doi.org/10.1021/j100873a014. 